\title{
worldview
}

\section{ANOTHER GREAT DEBATE-OR THINKING THE UNTHINKABLE}

Has Senator J. W. Fulbright opened the way for a much-needed debate on our foreign policy? Or has he, as some have suggested, simply resurrected myths which were, supposedly, once laid securely to rest? Will his speech lead to another great debate or will it join those other criticisms; considered but "unthinkable," that have been respectfully bowed into a political limbo?

There are some reasons to believe that his questioning of assumptions common both to the citizen and the policy-maker will throw open for discussion many practices and policies our government has been pursuing since the end of world war two. His position as chairman of the Foreign Relations Committee and his deserved reputation would have assured a hearing for any major foreign policy address he delivered. There are, however, additional and more substantial reasons for thinking that the Senator's comments will be the focus of a debate.

For all their effect, the ideas advanced by Senator Fulbright are not wholly novel. He has, in fact, aligned himself with a number of prominent spokesmen who have previously called for a renewal of our foreign policy. He has gone beyond them in one sense, however, by the force and particularity of his views. He has named as "myths" certain long-held assumptions about our relations with "the Communist bloc," with Communist China, with Cuba, with Panama. It is at the point of particular problems, of course, that the issue is joined. And already a small chorus of loud, and sometimes persuasive, dissenting voices has been heard from.

The "Communist bloc," these voices say, is still effectively united in its unrelenting hostility to the West, China represents a growing threat the end of whose growth is not yet in sight, Cuba is an intolerable affront and a real danger to Latin America, the Panama Canal is not only valuable but the struggle for its control represents a test case for U.S, determination. To swerve from the long-held assumptions on which these conclusions are based is, they suggest, to pass from strength to weakness, from resolution to indecisiveness, from a position of integrity to one of possible appeasement. These sentiments are, of course, the familiars of our political life, the very ones that Senator Fulbright and others would dismiss as anachronisms.

What Senator Fulbright has called into question, apart from the particular issues which are undoubtedly crucial test cases for our response, is our ability to perceive the world as it exists and to form a course of action consonant with reality. He has pointed out, what is increasingly apparent, that our present policies were designed for the recent past, are only dangerously serviceablo at present and will be entirely unsuitable for the near future. The constellations of power that came into being after the war have been scattered and rearranged. Yet we still feel threatened by the same dangers, throw up the same defenses and offer to other countries the same attractions that we did almost two decades ago. Our perceptions lag far behind the rapidly changing events.

If the anticipated debate develops it will have served a badly needed but primarily critical service. That is, it will have swept away encumbrances from the past; it will have cleared an area in which new, appropriate policies may be designed; it will have discarded the general umbrella of "cold war" under which have sheltered both valid and invalid assumptions of foreign policy. It will be then that our policy makers may truly be called upon to "think the unthinkable," for then they will be in a better position to formulate the limited goals proper to a state even so powerful as the U.S. This task is so urgent that those of us who favor the debate in the terms proposed by the Senator have a positive responsibility to see that it does not degenerate into the lowest level of campaign politics. 